\title{
Effect of Helicobacter pylori colonisation on gastric mucosal eicosanoid synthesis in patients taking non- steroidal anti-inflammatory drugs
}

\author{
N Hudson, M Balsitis, F Filipowicz, C J Hawkey
}

\begin{abstract}
Colonisation with Helicobacter pylori may influence susceptibility to gastroduodenal injury and ulceration in patients taking nonsteroidal anti-inflammatory drugs (NSAIDs). The aim of this study was to determine if Helicobacter pylori colonisation altered eicosanoid synthesis by gastric musoca in these patients. Sixty five patients with longstanding NSAID intake and 23 control subjects underwent endoscopy. In vitro gastric antral biopsies were stimulated by vortex mixing and eicosanoid measurements determined by radioimmunoassay. Helicobacter pylori colonisation was determined by a CLO test (a gel based rapid urease test) and histological assessment. Median prostaglandin $\mathrm{E}_{2}$ synthesis by gastric mucosa was 61.0 (interquartile range: $19 \cdot 2-73 \cdot 1) \mathrm{pg} / \mathrm{mg}$ in control subjects colonised with Helicobacter pylori compared with 46.5 (23.3-65.5) $\mathrm{pg} / \mathrm{mg}$ in Helicobacter pylori negative subjects. This was not significantly different. Treatment with NSAIDs was associated with a significant difference $(\mathrm{p}<\mathbf{0 . 0 0 1})$ in prostaglandin $\mathrm{E}_{\mathbf{2}}\left(\mathrm{PGE}_{2}\right)$ synthesis between those colonised with Helicobacter pylori $(37.5(22 \cdot 0-77 \cdot 3) \mathrm{pg} / \mathrm{mg})$ compared with patients not infected $(12 \cdot 6(7 \cdot 0-19 \cdot 3) \mathrm{pg} / \mathrm{mg})$. Values in patients taking NSAIDs who were colonised were not different from control subjects. Synthesis of PGE $_{2}$ was strongly associated with type $B$ (chronic active), but not type C (chemical) gastritis. Dyspeptic symptoms were more common in subjects colonised with Helicobacter pylori $(\mathrm{p}<0.002)$ and were associated with higher $\mathrm{PGE}_{2}$ synthesis. In patients taking NSAIDs Helicobacter pylori colonisation removes rather then enhances depression of $\mathrm{PGE}_{2}$ synthesis associated with NSAIDs and may promote dyspepsia associated with ulcers and prevent superficial mucosal injury.

(Gut 1993; 34: 748-751)
\end{abstract}

Department of

Medicine

N Hudson

F Filipowicz

C J Hawkey

Department of Pathology, University Hospital, Nottingham M Balsitis

Correspondence to: Professor C J Hawkey, Department of Medicine, University Hospital, Nottingham NG7 2UH.

Accepted for publication 3 November 1992
Both Helicobacter pylori and non-steroidal antiinflammatory drugs (NSAIDs) are well established risk factors for gastric and duodenal ulceration $^{12}$ but interactions between them are poorly described. It has been reported that patients taking NSAIDs experience more dyspepsia and have more chronic ulcers if they are colonised by Helicobacter pylori than if they are not. ${ }^{3-5}$ By contrast there seems to be no increase, or even a decrease, in less serious gastric mucosal injury. ${ }^{4}$

Prostaglandins are well recognised as protecting the gastric mucosa and enhancing the per- ception of pain. Inhibition of prostaglandin synthesis by NSAIDs is the major established mechanism by which NSAIDs render the gastric mucosa vulnerable to mucosal injury. ${ }^{6}$ Equally depression of prostaglandin synthesis, by diminishing pain perception, could at least in part account for the high proportion of NSAID associated ulcers that are silent. ${ }^{7}$

In theory the increased risk of peptic ulceration in patients taking NSAIDs who are infected by Helicobacter pylori could be explained if Helicobacter pylori acted to exaggerate the inhibition of prostaglandin synthesis by NSAIDs. Conversely, the increased dyspepsia and the decrease in superficial mucosal injury (if real) imply an opposite action with Helicobacter pylori restoring the mucosal prostaglandins to concentrations capable of mediating pain and of protecting the mucosa against injury. Previous data on the influence of Helicobacter pylori on synthesis of eicosanoids have been inconclusive. Two studies have found increased (but not significant) gastric prostaglandin $\mathrm{E}_{2}\left(\mathrm{PGE}_{2}\right)$ synthesis in the presence of Helicobacter pylori colonisation ${ }^{89}$; the rise in $\mathrm{PGE}_{2}$ synthesis was strongly associated with the intensity of inflammatory cell infiltrate. By contrast a third smaller study claimed depressed $\mathrm{PGE}_{2}$ synthesis, but surprisingly found no relation between production of $\mathrm{PGE}_{2}$ and polymorphonuclear cell infiltrate. ${ }^{10}$

The aim of this study was therefore to investigate the relation between Helicobacter pylori colonisation, symptoms, mucosal damage, and synthesis of eicosanoid by gastric mucosa, as detected by $\mathrm{PGE}_{2}$ and thromboxane $\mathrm{B}_{2}\left(\mathrm{TXB}_{2}\right)$ concentrations, in patients taking NSAIDs compared with control subjects.

\section{Patients and methods}

Sixty five patients with rheumatoid arthritis $(\mathbf{n}=$ 57) or osteoarthritis $(n=7)$ and taking NSAIDs for a period of greater than three months (mean 4.5 (SD 3.1) years) were recruited from a rheumatology clinic to undergo a screening upper gastrointestinal endoscopy before entry into a therapeutic trial that had been approved by the hospital ethics committee. Patients who had undergone previous gastric surgery, or were taking cytotoxic drugs or prednisolone at a dose greater than $5 \mathrm{mg}$ each day were excluded. Patients taking second line antiarthritic treatment were included in the study. Patients taking $\mathrm{H}_{2}$ antagonists stopped the medication at least one week before endoscopy. No patients had taken antibiotics for at least one month before endoscopy. Informed consent was obtained and patients were questioned as to whether they had 
experienced any upper abdominal pain or heartburn in the two weeks before endoscopy. At endoscopy a visual assessment of injury was made. Nine gastric antral biopsies were taken 3 to $4 \mathrm{~cm}$ from the pyloric ring. One sample was placed in a CLO test (a gel based rapid urease test) for assessment of Helicobacter pylori state (a positive result denoted by a colour change at four hours). Two samples were placed in formalin and subsequently stained for histological assessment. Paraffin sections were cut and stained with both haematoxylin and eosin and giemsa for evidence of gastritis and Helicobacter pylori organisms. Gastritis was defined according to the system proposed by Wyatt and Dixon. ${ }^{11}$ Histopathology assessments were made without knowledge of the endoscopic and biochemical findings.

The remaining biopsies were divided into pairs and washed in $1 \mathrm{ml}$ of Tris saline buffer. Each pair was then vortex mixed for six seconds and centrifuged for 10 seconds. The supernatant was stored and the procedure repeated. A further $300 \mu \mathrm{l}$ of Tris saline was added. Eicosanoid synthesis was stimulated by vortex mixing for a further minute. After centrifuging for 10 seconds the supernatant was removed and stored at $-70^{\circ} \mathrm{C}$ until assayed. Concentrations of $\mathrm{PGE}_{2}$ and $\mathrm{TXB}_{2}$ were measured by radioimmunoassay and the results expressed as $\mathrm{pg} / \mathrm{mg} /$ wet weight of gastric biopsy. Chemicals for radioimmunoassay were obtained from Amersham International except $\mathrm{PGE}_{2}$ antisera, which was from Sigma Chemicals Limited and $\mathrm{TXB}_{2}$ which was donated by Dr Lawrence Levine. Sensitivities and cross reactivities of all three assays have been previously described. ${ }^{12} 13$

\section{STATISTICAL ANALYSIS}

The influence of age, sex, smoking category, use of prednisolone or second line treatment, Helicobacter pylori colonisation and use of NSAIDs on each of the dependent variables was analysed by stepwise multivariate regression analysis with the SPSS (statistical package for social sciences) programme. The Mann-Whitney $\mathrm{U}$ test was then used for pairwise comparisons. The $\chi^{2}$ test was used to determine significant differences in gastroduodenal injury and symptoms between Helicobacter pylori positive and negative subjects. Results are expressed as medians (interquartile ranges).

\section{Results}

\section{PATIENTS}

Of the 65 patients taking NSAIDs, 25 (38\%) were colonised with Helicobacter pylori. Twelve ( $52 \%$ ) of the 23 control subjects were colonised with the organism. In the users of NSAIDs gastroduodenal ulceration occurred in six (24\%) of those colonised compared with three $(8 \%)$ of those who were Helicobacter pylori negative whereas erosions occurred in eight $(32 \%)$ who were Helicobacter pylori positive and in nine (23\%) of those Helicobacter pylori negative. The number of erosive lesions, as classified by ulceration or non-haemorrhagic erosions, was higher in
Patient characteristics and Helicobacter pylori colonisation of patients on NSAIDs treatment and conrols

\begin{tabular}{lll}
\hline & $\begin{array}{l}\text { NSAIDs } \\
(n=65)\end{array}$ & $\begin{array}{l}\text { Controls } \\
(n=23)\end{array}$ \\
\hline Male:female & $27: 38$ & $11: 12$ \\
Mean (SEM) age (yr) & $58 \cdot 0(1 \cdot 3)$ & $58 \cdot 9(2 \cdot 4)$ \\
Smokers (\%) & $16(25)$ & $8(30)$ \\
Mean (SD) duration of NSAID treatment & $4 \cdot 5(3 \cdot 1)$ & - \\
Helicobacter pylori colonisation (\%) & $25(38)$ & $12(52)$ \\
Endoscopic injury: & 9 & 5 \\
$\quad$ Ulcers & 17 & 5 \\
Erosions & 16 & 0 \\
Haemorrhages & 23 & 13 \\
Normal & & \\
\hline
\end{tabular}

the patients colonised with Helicobacter pylori $(\mathrm{p}<0 \cdot 1)$. Haemorrhagic lesions also occurred more frequently in subjects infected with the organism (36\% v 13\%; p<0.01) (Table).

\section{Symptoms}

Twenty four (37\%) of the patients taking NSAIDs had symptoms attributable to the upper gastrointestinal tract in the two weeks before endoscopy. Of these, $45 \%$ had complained of upper abdominal pain and heartburn, $36 \%$ of upper abdominal pain only, $18 \%$ of heartburn only. There was a significant difference in symptoms according to whether the subject was colonised with Helicobacter pylori or not. Sixteen (66\%) of the symptomatic patients taking NSAIDs were colonised with Helicobacter pylori compared with nine (22\%) of the patients with no symptoms $(\mathrm{p}<0.002)$.

\section{Gastritis}

Twenty (31\%) patients taking NSAIDs had a histologically normal gastric antral mucosa. Twenty (31\%) patients had a type C (chemical) gastritis and the remaining $25(38 \%)$ had a type B (chronic active) gastritis. Helicobacter pylori organisms were identified in all but two patients with type B gastritis and in two patients with type $\mathrm{C}$ gastritis. In the 12 control subjects with type B (chronic active) gastritis all were Helicobacter pylori positive whereas the antral mucosa of those not infected was histologically normal. The table gives other patient characteristics.

\section{PROSTAGLANDIN E}

The use of NSAIDs and colonisation by Helicobacter pylori were the only independent variables that influenced $\mathrm{PGE}_{2}$ concentrations. Synthesis of $\mathrm{PGE}_{2}$ in control subjects colonised with Helicobacter pylori was $61 \cdot 0(19 \cdot 2-73 \cdot 1)$ $\mathrm{pg} / \mathrm{mg}(\mathrm{n}=12)$, not significantly different from $46.5(23 \cdot 3-65 \cdot 5) \mathrm{pg} / \mathrm{mg}(\mathrm{n}=11)$ in subjects not colonised. In patients taking NSAIDs who were not colonised with Helicobacter pylori median synthesis of $\mathrm{PGE}_{2}$ by gastric mucosa was $12 \cdot 6$ $(7 \cdot 0-19 \cdot 3) \mathrm{pg} / \mathrm{mg}(\mathrm{n}=40)(\mathrm{p}<0.001 v$ controls $)$. In patients taking NSAIDs who were colonised with Helicobacter pylori synthesis of $\mathrm{PGE}_{2}$ was $37 \cdot 5(22 \cdot 0-77 \cdot 3) \mathrm{pg} / \mathrm{mg}(\mathrm{n}=25)$, significantly higher than in patients taking NSAIDs who were not colonised $(p<0.001)$ but not significantly different from values seen in comparable controls $(\mathrm{p}=0.52)$ (Figure). 


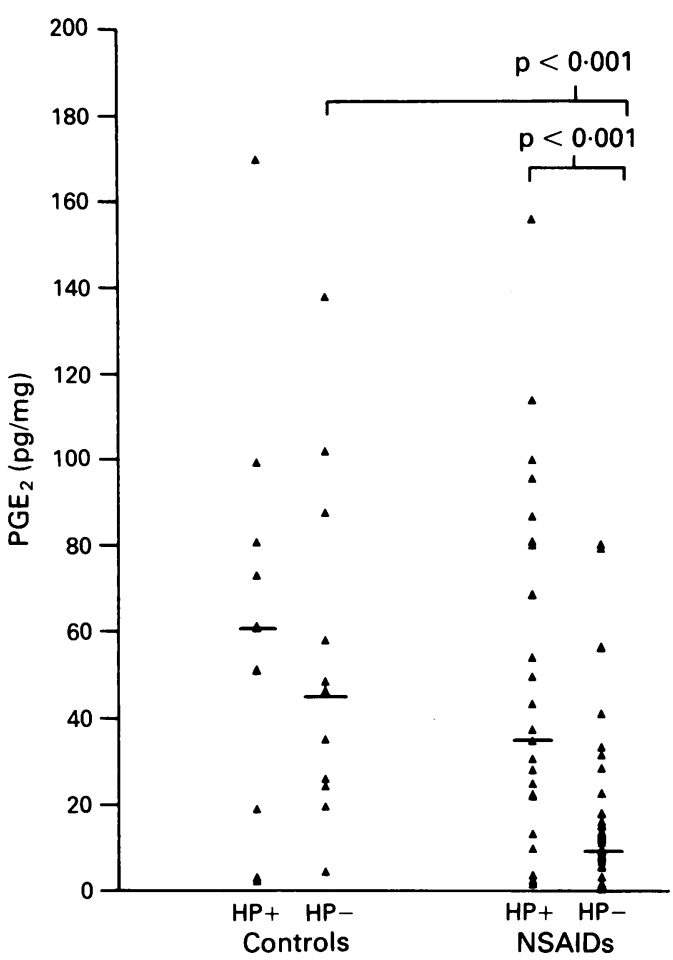

Influence of Helicobacter pylori colonisation $(H P)$ on gastric mucosal prostaglandin $E_{2}\left(P G E_{2}\right)$ synthesis in NSAID users and non-users. Medians denoted by bar lines.

\section{Gastritis}

Synthesis of $\mathrm{PGE}_{2}$ was also determined in subjects according to the histological state of the antral biopsies. All control subjects with type B (chronic active) gastritis were Helicobacter pylori positive with median $\mathrm{PGE}_{2} 61 \cdot 0(19 \cdot 2-73 \cdot 1)$ $\mathrm{pg} / \mathrm{mg}$. The antral mucosa of those not infected was histologically normal with median 46.5 $(23 \cdot 3-65 \cdot 5) \mathrm{pg} / \mathrm{mg}$. In patients taking NSAIDs those with type $B$ (chronic active) gastritis synthesised $43 \cdot 4(15 \cdot 6-80 \cdot 3) \mathrm{pg} / \mathrm{mg}$ of $\mathrm{PGE}_{2}$. This was significantly higher than the median $11 \cdot 4(7 \cdot 8-15 \cdot 4) \mathrm{pg} / \mathrm{mg}$ in patients with normal mucosa $(\mathrm{p}<0.001)$ and the median 13.1 $(5.9-25.0) \mathrm{pg} / \mathrm{mg}$ in patients with type C (chemical) gastritis $(p=0.012)$ and not significantly different from the value from patients not taking NSAIDs who had gastritis.

\section{Mucosal injury}

Median synthesis of $\mathrm{PGE}_{2}$ in patients taking NSAIDs with erosive lesions was $15 \cdot 4(6 \cdot 4-40 \cdot 3)$ $\mathrm{pg} / \mathrm{mg}$ compared with $16 \cdot 2(7 \cdot 50-38 \cdot 4) \mathrm{pg} / \mathrm{mg}$ in patients with haemorrhagic lesions or endoscopically normal mucosa. In patients who were colonised with Helicobacter pylori mucosal $\mathrm{PGE}_{2}$ concentrations were lower in subjects with erosive lesions compared with those with haemorrhagic lesions $(30.8(6 \cdot 2-63.8) \mathrm{pg} / \mathrm{mg} v$ $45 \cdot 8(22 \cdot 5-80 \cdot 1) \mathrm{pg} / \mathrm{mg})$.

\section{Symptoms}

In patients taking NSAIDs with symptoms attributable to the upper gastrointestinal tract $\mathrm{PGE}_{2}$ synthesis was $26.6(8 \cdot 5-68 \cdot 8) \mathrm{pg} / \mathrm{mg}$. Although this was higher than $13.8(7 \cdot 7-30.3)$ $\mathrm{pg} / \mathrm{mg}$ in subjects without symptoms, this did reach statistical significant $(p=0 \cdot 11)$.
Smoking

Although $\mathrm{PGE}_{2}$ synthesis was lower in patients taking NSAIDs who smoked compared with non-smokers this did not reach significance $(8.5$ $(2 \cdot 4-24 \cdot 9) v 18 \cdot 1(9 \cdot 8-46 \cdot 5) \mathrm{pg} / \mathrm{mg}(\mathrm{p}=0 \cdot 076))$.

THROMBOXANE $B_{2}$

Median gastric mucosal $\mathrm{TBX}_{2}$ synthesis was $27 \cdot 7$ $(13.0-53.7) \mathrm{pg} / \mathrm{mg}$ in patients taking NSAIDs compared with $39.8(10 \cdot 2-54 \cdot 2) \mathrm{pg} / \mathrm{mg}$ in control subjects. This difference was not significant. Colonisation with Helicobacter pylori did not significantly affect $\mathrm{TXB}_{2}$ synthesis in NSAID users. Those colonised with the organism produced $48.9(15.4-59.0) \mathrm{pg} / \mathrm{mg}$ compared wth $18 \cdot 3(12 \cdot 2-33 \cdot 2) \mathrm{pg} / \mathrm{mg}$ in those not colonised $(\mathrm{p}=0 \cdot 08)$. In control subjects not taking NSAIDs synthesis of $\mathrm{TXB}_{2}$ was not influenced by Helicobacter pylori $(42 \cdot 2(13 \cdot 5-61 \cdot 5) \mathrm{pg} / \mathrm{mg} v$ $30.9(6.9-45 \cdot 6) \mathrm{pg} / \mathrm{mg}$ respectively).

\section{Discussion}

The results of this study suggest that Helicobacter pylori removes rather than enhances the decrease in gastric mucosal $\mathrm{PGE}_{2}$ associated with NSAIDs. Age, sex, and use of prednisolone or second line treatment did not seem to influence $\mathrm{PGE}_{2}$ synthesis. Smoking has previously been reported to inhibit synthesis of $\mathrm{PGE}_{2}$ by gastric mucosa. ${ }^{14-16} \mathrm{We}$ also found lower concentrations in smokers although this did not reach significance. The increase in $\mathrm{PGE}_{2}$ associated with Helicobacter pylori seems likely to be a consequence of the associated inflammatory cell infiltrate as it was seen in patients with type $B$ (chronic active) but not with type $\mathrm{C}$ (chemical) gastritis, which is characterised by a paucity of inflammatory cells. ${ }^{1}$ Helicobacter pylori also tended to increase thromboxane $B_{2}$ synthesis although this was not statistically significant.

There is conflicting evidence concerning $\mathrm{PGE}_{2}$ concentrations in both peptic ulcer disease and mucosal inflammation. Some authors have suggested that $\mathrm{PGE}_{2}$ synthesis is increased in patients with gastric ulcers, ${ }^{17}$ and others have found no differences ${ }^{12}$ or depressed ${ }^{18}{ }^{19}$ synthesis, although the last may reflect occult aspirin or NSAID consumption. Similarly, $\mathrm{PGE}_{2}$ synthesis has been reported to be both reduced and increased in patients with superficial gastritis. ${ }^{12} 18$ Acute mucosal injury does not seem to be associated with stimulation of $\mathrm{PGE}_{2}$ synthesis. ${ }^{20}$ In vitro experiments suggest that Helicobacter pylori may even intensify the inhibition of $\mathrm{PGE}_{2}$ synthesis associated with administration of indomethacin..$^{21}$ Our data support the trends, however, reported in smaller studies by Taha et $a l^{8}$ and Avunduk et al ${ }^{9}$ that Helicobacter pylori seems to increase $\mathrm{PGE}_{2}$ concentrations in the presence of NSAIDs.

Jones et al found that, in NSAID users, colonisation by Helicobacter pylori determined serologically was associated with significantly more dyspeptic symptoms and NSAID intolerance. ${ }^{3}$ Similarly our study found a strong association between dyspepsia and colonisation by Helicobacter pylori in patients taking NSAIDs. The enhanced synthesis of $\mathrm{PGE}_{2}$ seen in patients 
taking NSAIDs and infected with Helicobacter pylori might mediate the increased dyspepsia that characterises these patients. In support of this we also found that $\mathrm{PGE}_{2}$ synthesis was increased in patients with dyspepsia compared with patients without symptoms although this did not reach statistical significance. Epidemiological evidence suggests that complications associated with NSAIDs are characterised by a paucity of premonitory symptoms. As many as $70 \%$ of patients presenting with ulceration may have no symptoms. ${ }^{7223}$ It is possible that patients colonised with the organism selectively stop their NSAID treatment because of dyspeptic symptoms.

Recent evidence suggests that Helicobacter pylori and ingestion of NSAIDs may interact to influence and enhance the susceptibility to gastroduodenal ulceration. Martin et al found that among Helicobacter pylori positive patients ingestion of NSAIDs significantly increased the risk of gastric ulceration. ${ }^{5}$ Others have suggested a similar interaction. ${ }^{34}$ Our data suggest that it is unlikely that the mechanism of this apparent synergy is enhanced depression of prostaglandin synthesis. It seems more likely that prostaglandin independent actions such as increased gastrin or acid production, or local production of toxins against epithelial cells account for this amplified impairment in mucosal defence. ${ }^{24} 25$

Endoscopically ingestion of NSAIDs is associated with a high prevalence of superficial mucosal injury. Graham et al have reported that in patients taking NSAIDs the associated mucosal injury of erosions and intramucosal haemorrhages is more frequent in those patients not colonised with Helicobacter pylori. ${ }^{4}$ In theory the increased prostaglandin synthesis seen with Helicobacter pylori might explain such a reduction in minor mucosal injury. A reduction in haemorrhagic lesions and increased prostaglandin synthesis in association with Helicobacter pylori and gastritis would be compatible with data showing that prostaglandins can exert protective properties at a vascular level. In our study, however, although there was a trend to higher prostaglandin concentrations in Helicobacter pylori positive patients with lower levels of mucosal injury this was weak. Moreover, we failed to find that Helicobacter pylori is associated with reduced acute mucosal injury and the relevance of haemorrhagic lesions in patients taking NSAIDs to the development of important clinical lesions has recently been questioned. ${ }^{26}$

In conclusion, we investigated the influence of Helicobacter pylori colonisation on gastric mucosal eicosanoid synthesis in patients taking NSAIDs. We found no evidence that Helicobacter pylori potentiated the detrimental effects of NSAIDs on mucosal defence mediated by eicosanoids. In fact, Helicobacter pylori seemed to stimulate synthesis of $\mathrm{PGE}_{2}$ by promoting mucosal inflammatory cell infiltration. The effect on prostaglandin production might account for the increase in dyspepsia associated with NSAIDs in patients colonised with Helicobacter pylori and could also protect the mucosa from superficial injury induced by NSAIDs.
This work was previously presented at the British Society of Gastroenterology Autumn Meeting 1991.

1 Desforges JF. Helicobacter pylori and peptic ulcer disease [Editorial]. N Eng f Med 1991; 324: 1043-9.

2 Hawkey CJ. Non steroidal anti-inflammatory drugs and peptic ulcers. $B M \mathcal{F} 1990 ; 300$ : 278-84.

3 Jones STM, Clague RB, Eldridge J, Jones DM. Serological evidence of infection with Helicobacter pylori may predict gastrointestinal intolerance to non steroidal antiinflammatory drug (NSAID) treatment in rheumatoid arthritis. Brf Rheumatol 1991; 30: 16-20.

4 Graham DY, Lidsky MD, Cox AM, Evans DJ, Evans DG, Alpert $\mathrm{L}$, et al. Long term non steroidal anti-imflammatory drug use and Helicobacter pylori infection. Gastroenterology drug use and Helicobe

5 Martin DF, Montgomery E, Dobek AS, Patrissi GA, Peura DA. Campylobacter pylori, NSAIDs and smoking: risk factors for peptic ulcer disease. Am $\mathcal{F}$ Gastroenterol 1989; 84: 1268-72.

6 Hawkey CJ, Rampton DS. Prostaglandins and the gastrointestinal mucosa: are they important in its function, disease or treatment. Gastroenterology 1985; 89: 1162-88.

7 Mellum H, Stave R, Myren J, Osnes M, Hanssen LE, Mosvols $\mathrm{J}$, Hibnes K. Symptoms in patients with peptic ulcer and haematemesis and/or melaena related to the use of non steroidal anti-inflammatory drugs. Scand $\mathcal{F}$ Gastroenterol 1985; 20: 1246-8.

8 Taha AS, Boothman P, Holland P, McKinlay A, Upadhyay R, Kelly RW, et al. Gastric mucosal prostaglandin synthesis in the presence of Campylobacter pylori in patients with gastric the presence of Campylobacter pylon in patients with gastric ulcers and

9 Avunduk C, Suliman M, Gang G, Polakowski N, Eastwood $\mathrm{GL}$. Gastroduodenal mucosal prostaglandin generation in patients with Helicobacter pylori before and after treatment with Bismuth Subsalicylate. Dig Dis Sci 1991; 36: 431-4.

10 Goren A, Fotherby KJ, Shorthosue M, Wright DGD, Hunter JO. Campylobacter pylori and acid secretion [Letter]. Lancet 1989; ii: 212.

11 Wyatt JI, Dixon MF. Chronic gastritis: a pathogenetic approach. F Pathol 1988; 154: 113-24.

12 Hawkey CJ. Synthesis of prostaglandin $E_{2}$, thromboxane $B_{2}$ and prostaglandin catabolism in gastritis and gastric ulcer. Gut 1986; 27: 1484-92.

13 Hawthorne BA, Boughton-Smith NK, Whittle BJR, Hawkey CJ. Colorectal leukotriene $B_{4}$ synthesis in vitro in inflammatory bowel disease: inhibition by the selective 5-Lipoxygenase inhibitor BW A4C. Gut 1992; 33: 513-7.

14 Quimby GF, Bonnice CA, Burstein SE, Eastwood GL. Active smoking depresses prostaglandin synthesis in human gastric mucosa. Ann Intern Med 1986; 104: 616-9.

15 Hudson N, Daneshmend TK, Hurst S, Bhaskar NK, Brown NS, Hawkey CJ. Effect of smoking on prostaglandin, thromboxane and leukotriene synthesis by human gastric mucosa. Adv Prostaglandin Thromboxane Leukotriene Res mucosa. Adv Prosta

16 Cryer C, Lee E, Feldman M. Factors influencing gastroduodenal mucosal prostaglandin concentrations: roles of duodenal mucosal prostaglandin concentrations: roles
smoking and ageing. Ann Intern Med 1992; 116: 636-40.

17 Schegel W, Wenk W, Dollinger HC, Raptis S. Concentrations of prostaglandin A, E, and $F$ like substances in gastric mucosa of normal subjects and of patients with various gastric diseases. Clinical Science Molecular Medicine 1977; 52: 255 .

18 Wright JP, Young GO, Klaff LJ, Weerss LA, Price SK, Marks IN. Gastric mucosal prostaglandion $E_{2}$ levels in patients with gastric ulcer disease and carcinoma. Gastroenterology 1982; 82: 263-7.

19 Hillier K, Smith CL, Jewel R, Arthur MJP, Ross G. Duodenal mucosal synthesis of prostaglandins in duodenal ulcer mucosal synthesis of prostagla
disease. Gut 1985; 26: 237-40.

20 Hawkey CJ, Kemp RT, Walt RP, Bhaskar NK, Davies J, Filipowicz B. Evidence that adaptive cytoprotection is not mediated by prostaglandins. Gastroenterology 1988; 94: 94854.

21 Taha AS, Kelly RW, Gemmell CG, Lee FD, Russell RI. The interaction between Helicobacter pylori culture infiltrate and indomethacin: effects on the integrity of human gastric mucosa and its prostaglandin $E_{2}$ production in vitro. Aliments in Pharmacology and Theraputics 1990; 4: 265-73.

22 Somerville K, Faulkner G, Langman MJS. Non steroidal antiinflammatory drugs and bleeding peptic ulcer. Lancet 1986; i: $462-4$.

23 Skander MP, Ryan FP. Non steroidal anti-inflammatory drugs and pain free peptic ulceration in the elderly. $B M \mathcal{F} 1988$; 297: $833-4$.

24 Figura N, Gugliemetti P, Rossolini A, Barber A, Cusi G, Musmanno RA, et al. Cytotoxin production by Campylobacter pylori strains isolated from patients with peptic ulcers bacter pylori strains isolated from patients with peptic ulcers
and from patients with chronic gastritis only. $\mathcal{F}$ Clin and from patients with

25 Cave DR, Vargas M. Effect of a Campylobacter pylori protein on acid secretion by parietal cells. Lancet 1989; ii: 187-9.

26 Laine L. NSAID-induced gastroduodenal injury: what's the score? Gastroenterology 1991; 101: 555-7. 